\title{
FORSKNING/
}
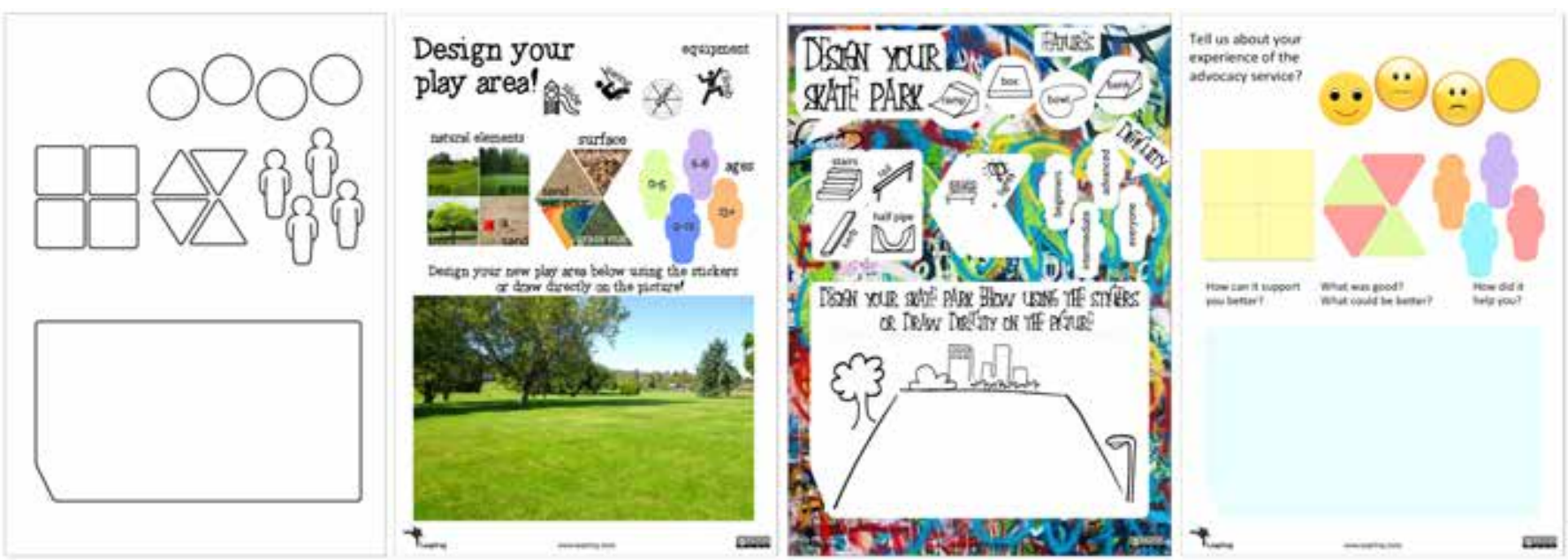

Figure 1. The Make It Stick template (left, with the cut lines of the stickers outlined here for legibility) and examples of adapted templates.

\section{Designing, Adapting and Selecting Tools for Creative Engagement: A Generative Framework}

\section{ABSTRACT:}

Increasingly public sector practitioners are turning to design to help them do more with less. This often takes the form of designing tools or resources that are used by public sector workers in their everyday practice. This paper critically examines the practice of tool design with the aspiration to improve creative engagement (that is, novel interactions that result in the creation of new knowledge or understanding in the public sector). We assert that designers should not be attempting to define what is a 'right' or 'wrong' way to use an engagement tool, but instead seek to enable new interpretations and adaptations of tools so the creativity of practitioners is supported and amplified. We present a proposal for a framework that supports people in organising the multitude of creative engagement tools in a manner that is meaningful to them rather than imposing taxonomies form the outside, enabling them to fix their own meanings, significance and use of the tools they use. To explore this we present 2 use cases, one by IRISS (a leader in innovation in the social services in Scotland) and a second by Leapfrog (a research project led by Lancaster University looking to transform public sector engagement by design).

We believe this change in the terms of reference when thinking about the creation and use of tools has profound implications for designers working in the social services and wider pubic services sector.

Keywords: tools, taxonomy, creative engagement, social services, scaffolding 


\section{INTRODUCTION}

In this paper we are concerned with how design can have a positive impact on creative engagement activities as part of social service provision. Here we define creative engagement activities as purposeful, skilful approaches to enable innovative, active and expressive dialogue between members of the public of all ages and social service professionals.

There are a great many people in the social services sector who are skilled at developing new engagement activities. However, people in this sector are also working under a range of pressures and do not always have the time to create or devise engagement activities (Iversholt et al., 20II). Social service workers have highlighted that there is a 'dearth of materials, resources, dedicated physical space, facilities and a lack of creativity' when working with people who access services (Winter, 2009). Responding to this it is clear there is a growing potential for social service practitioners to make use of designed materials, tools and related resources to support and structure professional interactions with people.

This paper proposes an approach to articulating the value and relevance of creative engagement tools that gives predominance to the skills and ingenuity of the social service workforce. We argue that the designers of engagement tools should be supporting and encouraging 'creativity in use' rather than seeking to prescribe how tools should be used or classified. We suggest that designers should not be attempting to define what is a 'right' or 'wrong' way to use an engagement tool, but instead seeking to enable new interpretations and adaptations of tools by those who use them. This is in tension with a taxonomic approach to organising and articulating the value of engagement tools, in which tools sit within predefined and, we argue, fundamentally limiting categorisations. We promote an approach where practitioners respond to local conditions and needs, adapting tools or resources accordingly in ways that are potentially radically different to the expectations of the tool designer.

To pursue this overarching aim this paper firstly describes creative engagement activities and the kind of outcomes people experience when engaging with and in these activities, drawing out barriers which effect to their use in social services. This leads onto a discussion of traditional taxonomic approaches to organise engagement tools and presents an alternative approach using a generative framework.

This generative framework is in itself a creative engagement tool, designed by the authors to help the creation or relevant micro-taxonomies by practitioners. In this paper we examine the potential for application of this framework by using two creative engagement tools as test cases that we apply to the generative framework. Following this we conclude by discussing the implications of our generative framework and present research questions that would better enhance our understanding of challenges our perspective illuminates.

\section{Design and Creative Engagement in the Public Sector}

There are examples of excellent design input into social service development (and more broadly) in the public sector through initiatives such as dot initiatives and institutions such as Mindlab in Copenhagen, SILK (Social Innovation Lab Kent) and Super-Public in Paris. Designers have the disciplinary knowledge and skills to propose new forms of engagement, and to develop tools and resources to allow others to implement them. For designers working in this area, tools are often seen as a key means to support and trigger creative engagement (Sanders and Stappers, 2008; Cruickshank, 20I4; Manzini, 20I5). In this paper we consider how engagement tools can and do enable social service practitioners to undertake creative engagement activities, the barriers at play in this space, and propose a generative framework intended to enable social service professionals to find and articulate the value in using creative engagement tools. We propose this framework both as a practical resource for social service professionals looking to undertake creative engagement, and as a means for designers to better articulate the contribution they can make to engagement practice.

While the position taken in this paper is relevant across the UK and internationally we are basing much of this research on a long and deep engagement with the social services in Scotland, UK. Engagement activities between people in this context, like many others, are time bound and the positive impacts of using creative engagement tools are influenced by many constraints.

\section{CREATIVE ENGAGEMENT ACTIVITIES}

Gauntlett (2008) identifies a range of benefits that creative engagement can bring to understanding social situations and individuals within them. The seeds of creative engagement can be traced back to twentieth century experimental models for participatory, co-constructive and thoughtful and considered exploration (Dewey, I9I6; Freire, I970; Forester, I982; Sarkissian \& Wenman, 2010). These are now emerging as two distinct creative approaches, 'creative acts' and co-design (described below) which both skilfully employ purposeful activity to enable innovative, active and expressive dialogue between members of the public and social service professionals.

The first kind of creative engagement uses creative acts (making, modelling through different media including film, photography and storytelling) as a way of considering community and societal issues. Research into the partnerships between the Voluntary Arts and Community Sector, public and social service providers in the UK, gives evidence for the value of creative engagement between public bodies and citizens (Kagan \& Duggan, 20II; Clennon et al., 20I6). Value is demonstrated through the opportunity it affords for inclusivity of voices (Sarkissian et al., 20ıо; Kagan \& Duggan, 20II; Clennon et al., 20I6), and its ability to bridge divides. It converts 
historic norms of top-down engagement into the co-construction of new cultural practices and collaborative governance, with improved chances of long term success (Kagan \& Duggan, 20II; Clennon et al., 20I6).

A second form of creative engagement is co-design, a method designers use to avoid a top down approach across projects involving external stakeholders. It is a route to social innovation, creating frameworks through which stakeholders can drive creative decision-making activity, at any stage of a design process (Sanders and Stappers, 2008; Manzini, 20I5). The resultant framework can refer to both singular design initiatives and to the architecture of an overarching ecology of activity (Manzini, 20I5). Advocates of co-design as a route to social innovation regard it as both social conversation and a near inevitability of any design process in a networked society bound to engage with complex societal challenges (Manzini, 20I5; Leadbetter, 20I0). In such a process, non-professional designers are skilled, experienced and motivated enough to work alongside expert designers (Leadbetter, 20I0).

In the case of public services, experience and motivation is derived equally from the workforce and the beneficiaries of that service seen in examples of service, product and space co-design. This dual engagement is represented in the literature in the areas of health (Donetto et al., 20I5), public space (Cruickshank, Coupe \& Hennessy, 2013) and public services (Long, 20I5). This is especially relevant for the design of tools to be used by social services professionals, this area is an active area of design research, for example see the Leapfrog project (www.leapfrog.tools).

In both the more embedded 'creative acts' approach and the more projectcentric co-design, tools are often used to facilitate creative exchanges. In the following section we focus on these tools and how they can be organised and adapted to best suite applications in the social services sector.

\section{OUTCOMES AND BARRIERS WHEN USING TOOLS FOR CREATIVE ENGAGEMENT}

Like any other kind of tool, a tool intended for creative engagement is not used for its own sake. It supports the practice of engagement by performing a function to help people achieve their desired outcome (Conole, 2009). Outcomes in social services in Scotland relate to "the real improvements that people see in their communities and in their lives ${ }^{1}$. In this paper we are focusing on process and change outcomes. These include, for example, instances in which the way support is delivered means people feel valued and respected, and relate to improvements in their mental or emotional functioning. ${ }^{2}$

In practical terms a tool is a mediating artefact, designed to codify and structure the way people engage (Fill, 2005), as well as support cognitive processes (Norman, I99I). Examples of tools might include templates, pro-formas, maps and card decks directing individual or collaborative action. Tools of this nature are often theorised as boundary objects that seek to support people to reveal where their socio-cultural values, knowledge, experience and intentions converge and diverge. In doing so enabling them to learn about and acknowledge that neither side has full or even partial expertise in the other's domain (Bernstein, I97I; Engeström et al., I995; Star, I989; Suchman, I993).

Tools used in creative engagement activities can allow active dialogues between contrasting forms of expertise (and experience) with the tool helping to bridge between them. This engenders joint ownership of the issues that are being discussed and localises problem solving (Engeström et al., I995). Following from this, it is imperative that the design of a tool helps to capture multiple meanings and perspectives in a way that is interpretable to those involved in an activity (Hasu \& Engeström, 2000). The codes and structures a tool seeks to highlight and offer depend on the interpretation of information about the tool's intended use and an individual's interpretation of the tool itself (Crilly, 2oII). Consequently tools can be appropriated or used by people and become highly and uniquely structured through individual use (Star \& Griesemer, I989). The variety of engagement tools produced by designers has the potential of offering great value to anyone seeking to instigate and facilitate creative engagement activities. However, clarifying the intent of an engagement activity before discovering, selecting and using the tools to assist in it can be a substantial barrier to unlocking this value.

It is important to point out that we believe tools do not offer, structure, aid, prompt, encourage, reveal or reflect outcomes unless the people who are using them

I) create a facilitative and participatory space which enables people to openly share what they are thinking, feeling and learning with others during the engagement process.

2) Take the time to reflect on what they and others are hearing, seeing and doing.

We see the values and principles inherent in creating facilitative and participatory spaces and adopting periods of reflection as part of engagement practice as key to realising the outcomes people seek when utilising particular tools.

It can be hard to identify what makes a tool work well for everyone. However, through the process of reflective practice people have been able to identify that tools support creativity, inclusivity, reflection thinking using a holistic perspective (Gauntlett, 2008), and the visualisation of power dynamics and unconscious and influential biases and assumptions (Winter, 2009). Yet creative engagement tools produced by designers are not necessarily easily discovered, understood or adopted by social service practitioners (Cruickshank, 20I4; Donetto, et al. 20I5). Additionally, realising the kinds of outcome described here can be difficult for social service practitioners because the interactive space in which they work

1 http://www.gov.scot/resource/doc/130092/0031160.pdf, p31

2 https://www.iriss.org.uk/sites/default/files/iriss_leading_for_outcomes_a_guide_final-1.pdf 
can be highly challenging; people can be emotionally stressed and may find it difficult to express their views, feelings and needs (Smith et al., 20I0). This can equate to situations in which the inclusion of creative engagement activities is not appropriate. This also suggests social service interactions are also inherently complex and can have variable social and psychological dynamics that can include unacknowledged and uneven power dynamics. For example, social workers have expert knowledge of the social work system and evidence from conversations and observations is used to make judgments about if and how the state can enable people. While acknowledging this, people who access services don't tend to have access to this knowledge. If people and the tools they use do not address such uneven power dynamics, these dynamics could be reinforced and possibly exacerbated, undermining attempts for rapport, parity and an individual's sense of support in social service interactions. Finally, both people who access services and practitioners are engaging with one another in what can be an opaque service which is part of an ever changing system and structure. This means it can be difficult for people to understand how the creative engagement process they have participated in (and the outcomes they have realised) connects to wider system and structures.

In responding to these barriers there are calls for designers to better support and enable this workforce to 'take on ever more challenging and complex client groups that require more personalised services' (Meroni \& Sangiorgi, 20II; Cunningham et al., 20I5). Existing approaches that fit with such calls include those which critique and challenge organisational and cultural norms, new service designs and adaptations, new policy development and legislation, educational and training opportunities and lower caseloads. Whilst appreciating the need for these developments, this paper focuses on activities and tools for the opportunity they present to reflect 'invisible [yet] prevalent discourses' in systems, services and interactions (Winter, 2009). Tools that can empower people in the social services with the resources and knowledge to identify and devise responses so they experience outcomes that better enhance their lives.

\section{TRADITIONAL TAXONOMIC AP- PROACHES TO ENABLING TOOL DISCOVERY AND SELECTION}

Taxonomies offer a means to systematise knowledge and practical resources, and so constitute a general strategy for connecting practitioners to new tools they could use in their work. Patrick Lambe (2007) describes three key attributes that define an effective taxonomy; providing a classification scheme that places related things together; providing a fixed and meaningful vocabulary; and producing a knowledge map to enable navigation between the things within it. As Lambe proposes, meeting these criteria requires deep engagement with the individuals who will use it, producing a sociallynegotiated scheme that in turn provides meaning and utility for those who create it (Lambe, 2007).

There is an argument that for tools to be meaningful when initially encountered the infrastructure (underpinning relational conventions and constraints) through which they are accessed must be sympathetic to the overall social context and daily practices in which it is embedded (Star \& Bowker, 2006; Bjögvinsson et al., 20I2). This requires knowledge of both practical application issues and related standards to help form a taxonomy of tools, which in a complex and mutable social context, must be both flexible and emergent (Bowker \& Star, 2005; Jewett and Kling, 1991).

We see taxonomic approaches deployed within the design research community as researchers seek enable practitioners to select appropriate tools for the situations they encounter in their work. Sanders, Brant and Binder (20I0) offer a framework with high level categories of form, purpose and context for participatory design (PD) tools, directly reflecting structures, terms and norms used by the
PD community. Alves and Nunes (2013) aggregate and classify methods and tools for service design by mapping them into an axis that can guide designers to select appropriate tools for their context, structured around Mager's processual categories of discover, reframe, envision and create (Mager, 2004). The literature also reflects more localised attempts to produce tool taxonomies. For example, Tarmizi and de Vreede (2005) analyse and categorise the facilitation tasks undertaken by communities of practice, using this analysis to create a taxonomy, and Walsh et al. (2013) offer a framework with eight dimensions for the classification of techniques used in intergenerational PD.

These taxonomic approaches seek to map out a generalised 'landscape' of tools, enabling practitioners to identify appropriate tools, and for researchers to identify opportunities to develop new or improved tools. Taxonomies of this kind need to be sufficient breadth to meaningfully organise tools within them, and be expressed with language that others will recognise and be able to use. The categories and terms chosen for this purpose are typically abstract, reflecting the knowledge structures, conventions and logics of a particular community or group. This is appropriate when consensus in practice and knowledge production is sought, but is in direct tension with tools intended to enable emergent, innovative and creative practices.

Here we argue that the flexibility and degree of emergence required for a taxonomy to really reflect the innovative applications that creative engagement tools can be put to by the social services workforce renders the taxonomic approach highly problematic, or even redundant. Instead of creating a top down hierarchical construct (even if it is in formed by working practices) we argue for a more pragmatic, responsive approach that supports the huge variety of social service practitioners to develop their own localised structures and characterisations, free from the influences of generalised frameworks intended to 
meet the needs of designers, researchers or broad communities of practice.

This rejection of an imposed 'metanarrative', that is an underlying message dictating how best to use the tools, is very well established in areas such as open design (Cruickshank, 20I4), democratised Innovation (von Hippel $\&$ Katz, 2002) and fundamentally in post-structuralist and object orientated philosophy (Bryant, 20I4). All these problematize the establishment of a fixed classification system to act as a system of control and argue for the deleterious effect this has on the ability of people involved in a process to maximise their own personal contribution. In the context of organising creative engagement tools to enable practitioners to discover and select them, a taxonomic approach imposes generalised expectations of tools use on working practices. While this could prove effective in a particular local context (such as a group of practitioners with shared practice and/or context), it could never capture the variety of possible tool use across the social services. It is the potential for variety and innovation through use that we are most concerned with, and how it can be encouraged and catalysed through the way tools are organised and encountered.

\section{GENERATIVE APPROACHES TO ENABLING TOOL DISCOVERY AND SELECTION}

Activating social service practitioners to discover and select and adapt tools for creative engagement is a challenging problem. For tools to be reusable in multiple contexts, and for them to provide opportunity for creative use and reinterpretation they must be presented in a form that is generalised. If the purpose of a tool is too tightly defined, then it is unlikely to fit with the diverse contexts and challenges such professionals face. At the same time however, if tools are presented in too general a form then they may fail to be meaningful or relevant to the understandings and contexts of professionals.

In this paper we put forward the argument that when seeking to enable non-designers to adopt creative engagement tools, the stability required for a successful taxonomy in vocabulary and ontology is unlikely to exist for an audience with diverse backgrounds and diverse contexts of work. More significantly, a stable top-down taxonomy would implicitly carry with it the notion that undertaking creative engagement is itself a stable and finite problem. In contrast, the authors' experience has shown that effective creative engagement requires strongly specialising tools and approaches to particular situations and contexts. A more productive strategy is to design tools that enable this specialisation at the point of use by public sector practitioners, the people who understand their context best and assist practitioners in constructing their own organising system or micro-taxonomy.

This approach enables discovery and selection of tools from a different direction, which explicitly emphasises the appropriation and adaptations professionals make when incorporating creative engagement tools into their practice. Rather than seeking to indicate how particular tools relate to general categories of use, this approach captures how tools have been specialised to fit with particular groups, situations and needs. The framework presented below enables tools users to reflect on how they use tools and generate bottom-up micro-taxonomies to help them use tools in their own innovative manner, not prescribed by designers.

\section{ENGAGEMENT TOOL ADAPTATION IN PRACTICE: MAKE IT STICK}

To translate this philosophical position into something more tangible for workers in the social services a project was undertaken to explore how social service practitioners adapt creative engagement tools in practice. This creative engagement project was called 'Make It Stick's. Make it Stick (MIS) worked with 20 people through 5 workshops with aim of facilitating the adaptation of a creative engagement tool. The funding for this tool (and MIS) came from the Leapfrog project, a three-year, $£$ I.2million project funded by the Arts and Humanities Research Council in the UK aiming to transform public sector engagement with citizens through design.

MIS used a tool developed by Leapfrog to enable creative engagement without the need for participants to write. Writing is a significant barrier for participants with low levels of literacy, where they are writing in a second language or where there are issues of trust in the authority that the social services represent. The tools consisted of a custom made set of stickers on a blank $\mathrm{A}_{4}$ sheet. These stickers (see Figure I, left) had generalised human forms, a range of basic shapes, and a large area for composing a new representation. The sticker sheet was designed to have graphics printed on them from a range of templates made available by the project with the aim of supporting a visual storytelling approach that did not require writing.

Initially a set of customisable digital templates were made available for people to download and print. However, we found that this was too restrictive the frames/templates developed by the designers on the project were not meeting the needs of the people downloading the tool.

MIS extended this beyond customisation to the point where participants were designing their own digital templates to exploit the physical sticker sheets. The researcher responsible for the project developed an interactive template that enabled people using it to not only change some of the text in the template, but to easily change almost any aspect of the graphics printed onto the sticker sheets. This sticker sheet acts as a support or a scaffolding to prompt creative adaption. Examples of different uses of this tool include a playground design, dog fouling and advocacy service experience (see Figure I). The tool has also been used in unexpected ways, for example one facilitator using the tool with a group of participants used lots of sticker sheets to create one large group storyboard. The aspiration for this project is that tool 
adaptors in the social services form an ecology of exchange around a platform such as a closed Facebook group.

\section{A GENERATIVE FRAMEWORK FOR TOOL DISCOVERY, SELECTION AND ADAPTATION}

The experience of MIS and other projects in Leapfrog (www.leapfrog.tools) led to the realisation that we needed a way to support the organisation and use of tools without imposing preferred uses or applications. The result was the formulation of a generalizable, generative approach to engagement tool use. This approach offers more utility and flexibility than offering a 'menu' of tools (and how they should be used) as commonly seen in taxonomic approaches. The approach has three loosely defined stages, informed not only by the MIS project but also more widely by work helping participants move out of their normal modes of working, for example the NETS project working with small high technology companies (see Mortati \& Cruickshank, 20I2).

Stage one: social service workers would be asked to think about a project or initiative in which they have successfully used an engagement tool. They would also be asked to describe their practice in terms of:

I) Their intention for the engagement activity that uses the tool

2) The situation they seek to support and enable (i.e. people involved, their history, needs, motivations, expectations and desired outcomes)

3) The fundamental capabilities they attribute to the tool.

The fundamental capabilities any tool offers is an area of potential debate. Drawing on an example of conventional physical tool use, a screw driver has a fundamental capability of rotating a screw, yet it can also be used as a lever to get the lid off a tin of paint or as a crude chisel. Equally for engagement tools they could be said to legitimately have many capabilities, here we want participants to

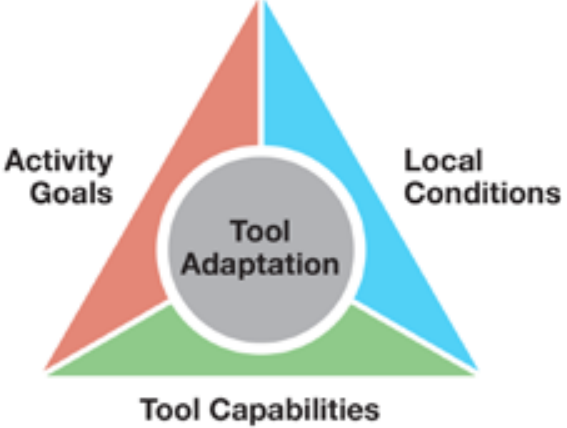

Figure 2. Tool use and adaptation framework.

think about the fundamental capabilities as they appear to them personally. These responses will depend on the experience, perspective and innate creativity of each participant. In this process all responses are correct if the participant in believes them to be convincing.

\section{Stage two invites practitioners to} describe how they were first exposed to the tool they successfully used, what form this took and critically how this was translated from initial form to practical implementation in their example. The aim here is to highlight past successful adaptations.

Stage three would introduce the diagram shown in Figure 2, bringing together the intention of tool use, the situation it is used in and expectations for what the tool can do. This 'prototyping' of tool use in a specific past context is intended to bring participants to a point where they are comfortable projecting into the future and actively considering their own tool adaptation. By moving towards adaptation of tools. The aim is to encourage practitioners to engage with creating their own collection of tools tailored to their own skills.

The diagram presented in Figure 2 can be expanded to encourage participants to think about how adaptations of the same tool can vary with different intentions and contexts for engagement. Figure 3 presents the general form all instances of the framework take; a matrix with goals arrayed on one axis and conditions on the other. When instantiated for a particular tool, additions can be made to both axes and descriptions of tool adaptations within the matrix itself. Adding to either axis prompts abstraction, grounded in the vocabulary of a particular context of practice, drawing out relevant features of engagement practice. Completing the body of the matrix prompts reflection on concrete choices made to adapt and use a tool in particular circumstances. Together the abstract and concrete elements of a framework instance are intended to capture the specific and transferable elements of tool use, acting as a reflective tool during population, and an accessible summary of tool adaptation that can be shared.

\section{APPLYING THE GENERATIVE FRAMEWORK TO REAL LIFE TOOLS}

To explore how the framework introduced in the previous section could function, we present two use cases of the framework populated with reference to tools the authors and public sector engagement practitioners have created and adapted for use in many contexts.

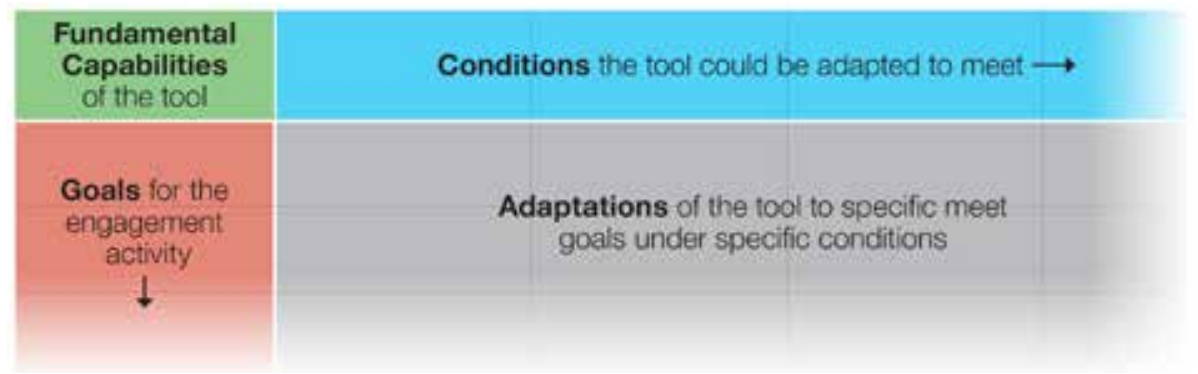

Figure 3. A generalizable form of the framework for participant created tool adaptation and organisation. 

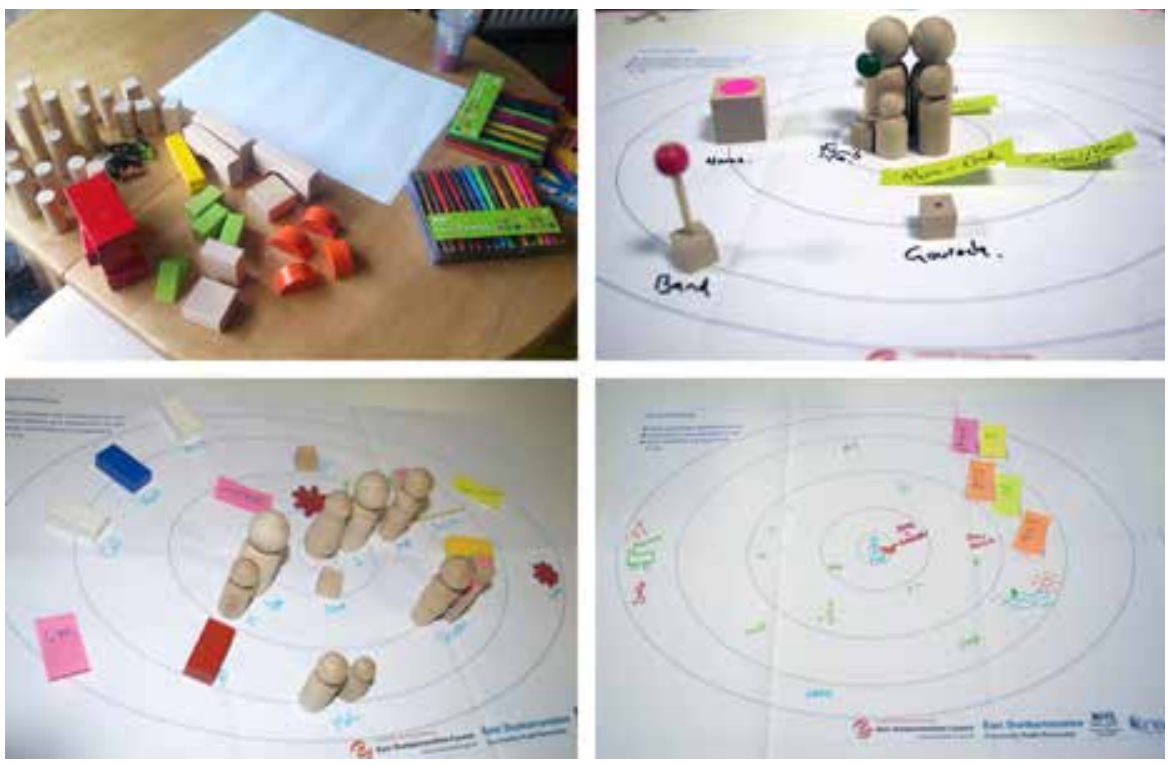

Figure 4. What's Important to You? Paper version before and after use.

\section{Case Study 1}

\section{- What's Important to You?}

The first example use of the framework is applied to the What's Important to You? (WITTY) tool. ${ }^{4}$ WITTY is an iPad app and paper-based tool that enables people to visually map positive assets and factors they have and can better engage with in day-to-day life. The tool is available in paper (Figure 4) and iPad form. The tool was designed to support people in visualising a personal interpretation of the positive assets in their life, identifying means to stay well, connected to these assets and happy. WITTY has been designed to be used as a reflective tool by one person, and as an aid in a one-to-one conversations and group discussions. WITTY can be used to help community members identify community and personal assets by creating a visual map of things a person has done in the past, things that exist in the present, or they would like to do in the future. The authors have found that when a participatory, asset based approach is engaged in to facilitate the use of this tool the imagery enables people to see 'the bigger picture' of their life, and identify things they like and are able to do when they are not feeling well. It can also support people to move from a deficit based model to an asset based perspective when thinking about a person's health.

Like many other tools suited to creative engagement, WITTY offers a set of flexible practical and conceptual resources that could be used in a wide variety of ways. Capturing some of this flexibility and potential, Table I applies the framework presented in the previous section to this tool. Here we see 2 examples of the type of goals and conditions that could have a bearing on the adaptation of the tool. This table could be developed into a participant-defined organisation of the way they have adapted tools. Also the participant would add their view of the fundamental properties of the tool.

In the example of tool adaptation here (the shaded box in Table I) WITTY has been adapted by the authors to draw out insights concerning the evaluation of past interventions when there is an uneven power dynamic (for instance in the often hierarchical organisational structures in the health service). The adaptations here are focused on helping people feel comfortable expressing their views through the creation of a safe space, through humour, through anonymity and through discussion amongst peers rather than hierarchical groups. There is also a suggestion for an adaptation to the graphic representation of the tool to help achieve the goal.

\section{Case Study 2 - Superheroes}

The second example use of the framework we present is applied to the Superheroes tools. The Superheroes tool was originally designed to enable workshop participants to explore the perceived, actual and desired characteristics of a group of people without adopting a negative perspective (see Figure 5).

The Superhero proforma offers a series of 'dotted' line suggestions that help an individual or group draw their own superhero on one half of the proforma and their normal alter-ego on the other. In addition to the superhero's costume, participants can be invited to think about special powers, tools and equipment and their 'kryptonite'. The metaphor of the superhero can be used to encourage a playful approach that suspends disbelief and encourages open, free thinking, in Huizinga's terms establishing a magic circle (Huizinga, 1944) where normal

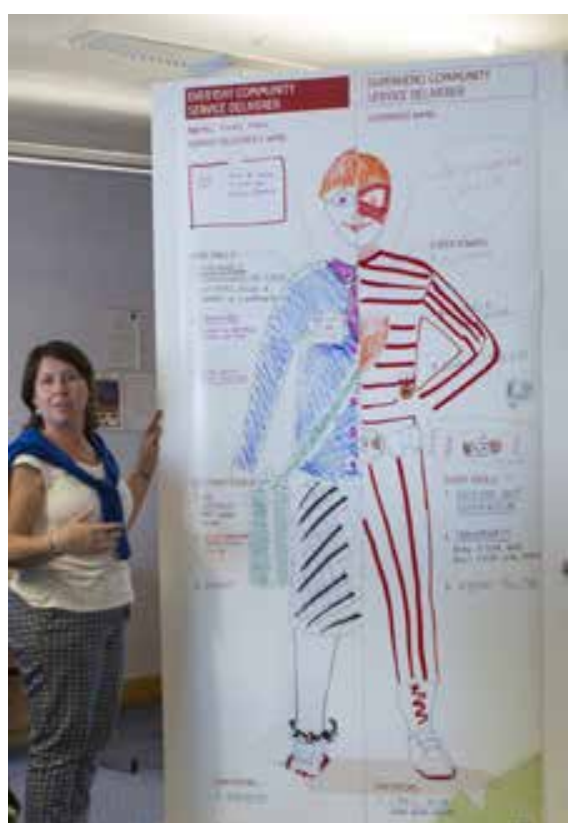

Figure 5. The Superhero Tool used to explore and compare the characteristics of policy makers, designers and frontline staff in the public sector. 


\begin{tabular}{|c|c|c|c|}
\hline \multirow{2}{*}{\multicolumn{2}{|c|}{$\begin{array}{l}\text { Fundamental Tool properties } \\
\text { Highlighting and better un- } \\
\text { derstanding interpretations of } \\
\text { assets in people's lives } \\
\text { Unexpected outcomes wanted }\end{array}$}} & \multicolumn{2}{|c|}{ Conditions the tool was be adapted to meet } \\
\hline & & Uneven power-dynamics & (Table headings continue)... \\
\hline 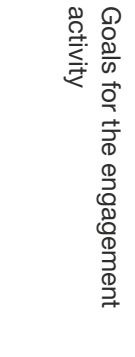 & Recognise assets & $\begin{array}{l}\text { Use WITTY in self defining } \\
\text { groups with similar levels } \\
\text { of authority }\end{array}$ & $\begin{array}{l}\text { Use WITTY in self defining } \\
\text { groups with similar levels of } \\
\text { authority } \\
\text { Use humour and different size } \\
\text { counters to encourage groups to } \\
\text { recognise power relationships. } \\
\text { Collective creation with no direct } \\
\text { feeding back. } \\
\text { Create a time machine metaphor } \\
\text { to help people 'think back' }\end{array}$ \\
\hline
\end{tabular}

Table 1. The engagement tool adaptation framework applied to the WITTY tool (section shown)

\begin{tabular}{|c|c|c|c|c|}
\hline \multirow{2}{*}{\multicolumn{2}{|c|}{$\begin{array}{l}\text { Fundamental Tool properties } \\
\text { Discussing hidden qualities in } \\
\text { a positive manner } \\
\text { Unexpected outcomes wanted }\end{array}$}} & \multicolumn{3}{|c|}{ Conditions the tool was be adapted to meet } \\
\hline & & Uneven power-dynamics & Participants don't & Time poor... \\
\hline \multirow{4}{*}{  } & $\begin{array}{l}\text { Build and } \\
\text { strengthen rela- } \\
\text { tionships }\end{array}$ & $\begin{array}{l}\text { Create superheroes for } \\
\text { contacts to map out a } \\
\text { shared social network. }\end{array}$ & & \\
\hline & $\begin{array}{l}\text { Recognise diverse } \\
\text { opinions }\end{array}$ & $\begin{array}{l}\text { Participant's fill out } \\
\text { each other's alter-egos, } \\
\text { surfacing hidden talents. }\end{array}$ & $\begin{array}{l}\text { Work in pairs to } \\
\text { identify super } \\
\text { powers, avoiding } \\
\text { individuals being } \\
\text { in the spotlight } \\
\text { alone. }\end{array}$ & $\begin{array}{l}\text { Imagine stories } \\
\text { about how the } \\
\text { superheroes } \\
\text { would collec- } \\
\text { tively change the } \\
\text { world, finding } \\
\text { common goals. }\end{array}$ \\
\hline & Plan and do work & $\begin{array}{l}\text { Focus on imaginary } \\
\text { superpowers, surfacing } \\
\text { frustrations and barriers. }\end{array}$ & & \\
\hline & [more] ... & & & \\
\hline
\end{tabular}

Table 2. The engagement tool adaptation framework applied to the Superheroes tool

rules do not apply. The difference between the everyday alter-ego with their fair share of flaws and vulnerabilities and the super-hero beneath the surface can be used a means to surface intentions, beliefs, assumptions, desires and possibilities.

The graphical form of the Superheroes does not necessarily constrain the variety of ways it can be used. Applying the framework presented in the previous section, in Table 2 the authors suggest a range of ways the tool can be adapted to enable creative engagement for different purposes and under different conditions. The framework shows how the original design intent behind the tool, to playfully surface individual characteristics, has been adapted to fit a number of different conditions and different goals for the application of the tool (highlighted in green). Each of these possible uses and adaptations of the Superheroes tool is particular to a situation or context that demands it, together mapping out a space of possible uses for the tool that may intersect with the experience or needs of an individual seeking to use the tool in their creative engagement practice.

\section{IMPLICATIONS AND DISCUSSION}

The examples presented here demonstrate a ground up, generative framework that supports the creation of local taxonomic structures that recognises and facilitates the creative abilities of social service practitioners, while avoiding imposing organising structures and principals from the outside. This offers a new dimension to design support for social services. Design is increasingly playing a part in public sector innovation, through design thinking, co-design and cocreation through to more formal service design interventions.

The argument and proposal presented here has profound implications for those designing tools to support creative engagement and for the role of social services practitioners in creative engagement processes. Rather than seeing tools as 'products' to be used by practitioners to help achieve something that otherwise would be difficult or impossible, we are proposing a change of mind-set on the part of the designer. Designers should be looking to create 'proto-tools' that balance fundamental properties:

I) The designer should be thinking in terms of 'pallets' or collections of tools that can be built by practitioners to suit their own practice, tools should 'talk to each other' not tie participants into closed systems. Practitioners should be assisted in building up a collection of tools that fit their skills and abilities.

2) Tools need to be immediately accessible to attract under-pressure social service practitioners. This entails them working reliably without adaptation or having to 'learn' how to use them. The function and application to the tool needs to be obvious. 
3) Tools also need to encourage modification and tailoring to the specific needs, imagination and context of the person using the tools. They should invite experimentation while also working well as they arrive (to meet the requirements of property one).

The notion of encouraging active curating of tools into personal collections and then adapting these to fit a specific need is critical here. Within the use of individual tools, what are the cues, affordances, constraints and indicators that reassure social service practitioners while at the same time drawing them into reflecting on how the tools can be developed to further improve their practice? The generative framework proposed in this paper is one possible approach to this, but we need to find better ways to both co-design flexible tools with practitioners and find new ways of working with practitioners to 're-co-design' tools to fit their own needs. The authors of this paper have started work in both of these endeavours (for example in April 20I6, 50 public sector practitioners came together to adapt flexible creative engagement tools specifically focused on working with young people) but there are still significant challenges ahead. We end with a call for dialogue, research and action to address four key problems:

How to encourage public sector workers to pause and reflect on the possibility that tools can offer tangible benefits to their practice while they are under incredible and increasing work pressure where facilitative and reflective space and time is not common?

How can we design ways of helping practitioners curate their tools in a natural way that does not introduce layers of bureaucratic or linguistic complexity?

How to design tools that social service professionals both to adapt to better fit their specific needs?

How to share this creative social service led adaptation / re-co-design to build a critical mass of adaptation that is self-sustaining?

\section{REFERENCES}

Alves, R., \& Nunes, N. J. (2013). Towards a Taxonomy of Service Design Methods and Tools, 4th International Conference on Exploring Services Science, IESS 20I3. Bernstein, B. (I97I). Class, Codes and Control. Volume I: Theoretical Studies Towards a Sociology of Language. London: Paladin.

Björgvinsson, E., Ehn, P., \& Hillgren, P. A. (20I2). Agonistic participatory design: working with marginalised social movements. CoDesign, 8(2-3), I27-I44.

Bryant, L. R. (20I4). Onto-Cartography. Edinburgh University Press.

Clennon, O. D., Kagan, C., Lawthom, R., \& Swindells, R. (20I6). Participation in community arts: lessons from the innercity. International journal of inclusive education, 20(3), 33I-346.

Conole, G. (2009). The role of mediating artefacts in learning design. In Handbook of Research on Learning Design and Learning Objects: Issues, Applications, and Technologies (pp. I88-208). IGI Global.

Crilly, N. (20II). The design stance in user-system interaction. Design Issues, 27(4), I6-29.

Cruickshank, M. L. (20I4). Open Design and Innovation: facilitating creativity in everyone. Gower Publishing, Ltd..

Cruickshank, L., Coupe, G., \& Hennessy, D. (20I6). Co-Design: Fundamental Issues and Guidelines for Designers: Beyond the Castle Case Study. Swedish Design Research Journal, 9(2), 46-57.

Cunningham, I., Lindsay, C., \& Roy, C. (20I5). People's experiences of working in social services: A qualitative analysis. Retrieved from http://blogs.iriss.org.uk/ viewfromhere/story-20I5/story-analysis/ ewss-qualitative-analysis-summary-20I5/
Dewey, J. (I9I6). Democracy and Education: An Introduction to the Philosophy of Education. The Macmillan Company.

Donetto, S., Pierri, P., Tsianakas, V., \& Robert, G. (20I5). Experience-based co-design and healthcare improvement: Realizing participatory design in the public sector. The Design Journal, I8(2), 227-248.

Engeström, Y., Engeström, R., \& Kärkkäinen, M. (I995). Polycontextuality and boundary crossing in expert cognition: Learning and problem solving in complex work activities. Learning and instruction, 5(4), 319-336.

Fill, K. (2005). A learning design toolkit to create pedagogically effective learning activities. Journal of Interactive Media in Education, 2005(I).

Forester, J. (I982). Planning in the face of power. Journal of the American Planning ssociation, 48(I), 67-80.

Freire, P. (I970). Pedagogy of the Oppressed. New York: Herder and Herder.

Gauntlett, D. (2007). Creative and reflective production activities as a tool for social research., ESRC Research Development Initiative: Building Capacity in Visual Methods, Introduction to Visual Methods Workshop, University of Leeds, Leeds.

Hasu, M., \& Engeström, Y. (2000). Measurement in action: an activity-theoretical perspective on producer-user interaction. International journal of humancomputer studies, 53(I), 6I-89.

Huitzinga, J. (I944). Homo Ludens: A study of the play element in culture. Routledge and Kegan Paul.

Iversholt, R., Pattoni, L., \& Iriss. (2OII). Embracing change: Five guides on the topic of innovation in social services in Scotland. Retrieved from https://www. iriss.org.uk/resources/reports/embracing-change 
Jewett, T., \& Kling, R. (I99I). The dynamics of computerization in a social science research team: A case study of infrastructure, strategies, and skills. Social Science Computer Review, 9(2), 246-275.

Kagan, C., \& Duggan, K. (20II). Creating community cohesion: the power of using innovative methods to facilitate engagement and genuine partnership. Social Policy and Society, Io(3), 393-404.

Lambe, P. (2007). Organising knowledge: taxonomies, knowledge and organisational effectiveness. Cambridge: Chandos.

Leadbeater, C. (20I0) We-think. Profile books.

Long, K. (20I5). New Spaces of Democracy. Designing Democracy Essay Collection: An Inquiry by The Design Commission, 39-40. Retrieved from http://www. policyconnect.org.uk/apdig/research/ designing-democracy-essay-collection

Mager, B. (2004). Service design: A review: Köln International School of Design.

Manzini, E. (20I5). Design, when everybody designs: An introduction to design for social innovation: MIT press.

Meroni, A., \& Sangiorgi, D. (2OII). Design for services. Gower Publishing, Ltd.

Mortati, M., \& Cruickshank, L. (2OI2). NETS: a design tool for activating social networks. International Journal of Entrepreneurial Behavior \& Research, I8(4), 509-523.

Norman, D. A. (I99I), "Cognitive artifacts", Designing interaction: Psychology at the human-computer interface, I, I7-38

Sanders, E. B. N., Brandt, E., \& Binder, T. (20IO). A framework for organizing the tools and techniques of participatory design. In Proceedings of the IIth bien- nial participatory design conference (pp. I95-I98). ACM.

Sanders, E. B. N., \& Stappers, P. J. (2008). Co-creation and the new landscapes of design. Co-design, 4(I), 5-I8.

Sarkissian, W., \& Wenman, C. (2010)

Creative community planning: Transformative engagement methods for working at the edge. Routledge.

Smith, M., Doel, M., Cooper, A., Simmonds, J., Solomon, R., Kohli, R., ... \& Parkinson, C. (2010). Relationship-based social work: Getting to the heart of practice. Jessica Kingsley Publishers.

Star, S. L. (I989). 'The structure of illstructured solutions: boundary objects and heterogeneous distributed problem solving (pp. 37-54).

Star, S. L., \& Bowker, G. C. (2006). How to infrastructure. Handbook of new media: Social shaping and social consequences of ICTs, 230-245.

Star, S. L., \& Griesemer, J. R. (I989). Institutional ecology,translations' and boundary objects: Amateurs and professionals in Berkeley's Museum of Vertebrate Zoology, I907-39. Social studies of science, I9(3), 387-420.

Suchman, L. (I993). Working relations of technology production and use. Computer Supported Cooperative Work, 2(I-2), 2I-39.

Tarmizi, H., \& de Vreede, G. J. (2005). A facilitation task taxonomy for communities of practice. AMCIS 2005 Proceedings, 485 .

Von Hippel, E., \& Katz, R. (2002). Shifting innovation to users via toolkits. Management science, 48(7), 82I-833.

Walsh, G., Foss, E., Yip, J., \& Druin, A. (20I3). FACIT PD: a framework for analysis and creation of intergenerational techniques for participatory design. In proceedings of the SIGCHI Confe- rence on Human Factors in Computing Systems.

Winter, K. (2009). Relationships matter: the problems and prospects for social workers' relationships with young children in care. Child \& Family Social Work, I4(4), 450-460. 